\title{
Effect of the removal of the barrier layer period in productive process for anodic alumina membrane
}

\author{
M. Ahmadi Daryakenari ${ }^{1}$, M. Zohrabi $^{2}$, A. Ahmadi Daryakenari ${ }^{3}$ \\ ${ }^{1}$ Kazan National Research Technological University, 68 K. Marksa Str, Kazan, Russia \\ ${ }^{2}$ Kazan Federal University, 18 Kremlin Str, Kazan, Russia \\ ${ }^{3}$ The University of Tokyo, 7-3-1 Hongo, Bunkyo-ku, Tokyo, 113-8656, Japan \\ dariakenari@gmail.com
}

DOI 10.17586/2220-8054-2016-7-6-906-910

\begin{abstract}
An anodic alumina membrane (AAM) is produced using two-step anodizing by using various types of acidic electrolytes, such as sulfuric acid, phosphoric acid and oxalic acid. Holes are characterized by hexagonal structure with diameters ranging from 40 to $420 \mathrm{~nm}$. Heat and chemical stability also regular formed holes are made the membranes appropriate for using in gas separating process, drug delivery and applicant for fuel cell membrane. Detaching of membrane from the aluminum base is the most important stage of the membrane production process. In this research, initially, the aluminum base layer was removed with the use of $\mathrm{CuSO}_{4}$ and $\mathrm{HCl}$. In secondary step, barrier layer at the end of the holes were removed with phosphoric acid solution. The aim of this work is to analyze the effect of time on the barrier layer removal process.
\end{abstract}

Keywords: alumina, nanopore, anodizing, phosphoric acid.

Received: 26 April 2016

Revised: 10 July 2016

\section{Introduction}

The use of anodized aluminum began only in the last century. The anodic behavior of aluminum was intensively investigated to obtain protective and attractive films on its surface. Currently, anodizing is defined as an electrochemical process of converting metal (usually aluminum) to metal oxide on the metal's surface. The electrochemical cell of anodizing consists of cathode, anode (the metal substrate to be converted to metal oxide) and direct current (DC) power supply. The anodic aluminum oxide thin film starts to grow at the anode (aluminum surface) as the anodic current or voltage is applied [1,2].

An anodic alumina membrane (AAM) can provide a simple template for deposition and the growth of various materials with ordered structures. A new two-step anodization method for the synthesis of porous aluminum oxide having regular structure in oxalic acid was invented by H.Masuda in 1995 [3]. After this invention, scientists have tried to discover new ways to synthesize this material with different characteristics.

The success of AAM is due to its attractive physical and chemical properties: its ceramic temperament involves high thermal strength (up to several hundred degrees) and excellent chemical insensitivity in many environments (from $\mathrm{pH}$ 's ranging from 5-9). It has highly-ordered nanopores with controllable and uniform dimensions arranged in a close-packed hexagonal footprint. AAM's with pore diameters ranging from 4-420 nm, density as high as $10^{11}$ pores $/ \mathrm{cm}^{2}$, and film thickness variable from $0.1-300 \mu \mathrm{m}$ have been obtained using two-step anodization or nanoimprint methods. These materials can be synthesized in slightly soluble electrolytes, such as sulfuric, phosphoric and oxalic acids [4,5].

The synthesis of nanomaterials such as polymeric nanowire, metallic nanowire [6], 3D nanodots [7], polymeric- [8] and metallic nanotubes [9], etc have given many research directions to anodic alumina membrane also because it can be used as membrane in various applications such as gas separation [10], drug delivery [11], in solid acid fuel cells [12] and solar cells [13].

A key difficulty encountered in the above-mentioned applications is how to attain through-hole porous anodic alumina which was previously produced on an alumina barrier layer covering aluminum substrate in the anodization process. Wet chemical etching founded on $\mathrm{H}_{3} \mathrm{PO}_{4}$ is commonly considered the most reliable method for custom pore opening of AAM $[14,15]$. The difficulty of this method is that the process of pore opening is controlled by the etching time, usually from 50-90 minutes. Different etching conditions, e.g. the concentration of $\mathrm{H}_{3} \mathrm{PO}_{4}$ $(5-10 \mathrm{wt} \%)$, temperatures $\left(25-50{ }^{\circ} \mathrm{C}\right)$ have been reported for pore opening of AAM, but there are no details on how these variations affect the pore diameters of AAM $[14,15]$. The aim of this work is to analyze the effect of time on the barrier layer removal process. The morphological modifications were monitored by Scanning Electron Microscopy (SEM). 


\section{Experimental procedures}

AA1057 aluminum (diameter $14 \mathrm{~mm}$, thickness $0.3 \mathrm{~mm}$ ) was used as the starting material. Active surface diameter of the samples was $10 \mathrm{~mm}$. The samples were disc-shaped to minimize both the uneven electric field during electropolishing (EP) and anodizing, and the undesirable effects of heat treatment such as remaining stress. Before anodizing, the aluminum was degreased with acetone and then annealed at $450{ }^{\circ} \mathrm{C}$ for 15 min. During the $\mathrm{EP}$, the aluminum specimens were electropolished in a mixture of ethanol- hydrochloric acid solution (1:4) at $35 \mathrm{~V}$ for $1 \mathrm{~min}$. To speed up the anodizing process, a polyethylene chemical reactor was designed which permitted the anodization of 4 specimens simultaneously. The temperature of the electrolyte was maintained at $17 \pm 0.1{ }^{\circ} \mathrm{C}$ by means of isotherm Lauda circular bath (RE106). AAM's were prepared in a two-step anodizing process. In the first step, aluminum specimens were anodized in $0.3 \mathrm{M}$ oxalic acid $\left(\mathrm{C}_{2} \mathrm{H}_{2} \mathrm{O}_{4}\right)$ electrolyte $40 \mathrm{~V}$ and $17{ }^{\circ} \mathrm{C}$. After $15 \mathrm{~h}$ of anodization, the specimens were immersed in a mixture of $0.5 \mathrm{wt} \% \mathrm{H}_{3} \mathrm{PO}_{4}$ and $0.2 \mathrm{wt} \% \mathrm{H}_{2} \mathrm{CrO}_{4}$ at $70{ }^{\circ} \mathrm{C}$ for $6 \mathrm{~h}$ to remove the alumina layers. The aluminum specimens were then anodized again for $24 \mathrm{~h}$ under the same anodization conditions used in the first step. The Current-Time diagram of the 2-nd anodizing at $40 \mathrm{~V}$, was drawn using multi-meter (Loutron 801) software. The film thickness was measured using a scanning electron microscope (SEM, XL30, Philips company). Since the layers are fragile, they are deeply cracked when curved. Hence, the thickness of oxide layer will be observed more easily and carefully using Scanning Electron Microscopy. X-Ray Diffraction (XRD) patterns of AAM were obtained by Philips PW1140 system. A saturated solution of copper sulfate and hydrochloric acid was used for dissolving the metallic base. Then, the membrane was immersed in $100 \mathrm{~mL}$ of $5.00 \mathrm{wt} \%$ phosphoric acid at $30.0^{\circ} \mathrm{C}$ for different periods of time $(30 \mathrm{~min}, 60 \mathrm{~min}$ and $90 \mathrm{~min})$.

\section{Result and discussion}

\subsection{Model of anodic alumina membrane}

The model of an AAM nanopore is shown in Fig. 1 by following a literature reference [16]. As indicated in the figure, $\mathrm{C}$ is the cell dimension (pore-to-pore distance) with cell wall thickness, $\mathrm{W}$ and $\mathrm{P}$ is the pore diameter, and $\mathrm{A}$ is the center of curvature that moves continuously during anodization toward the bottom. The active layer during nanopore growth is the barrier layer with thickness (d). There are two active interfaces associated with the barrier layer. The outer one is associated with oxidation of aluminum to aluminum cation $\left(\mathrm{Al} \rightarrow \mathrm{Al}^{3+}\right)$, and the inner one is associated with $\mathrm{O}^{2-}$ migration that leads to the formation of alumina $\left(\mathrm{Al}_{2} \mathrm{O}_{3}\right)$, as well as dissolution and deposition of alumina to and from the etching solution. The whole process is driven by the local electric field (E), which is defined by the current applied (I) over conductivity $(\sigma)$ and the surface area of the spherical bottom $\left(\frac{\omega}{4 \pi} \cdot 4 \pi b^{2}\right)$, where $\omega$ is the solid angle of the active barrier area and $b$ radius of curvature:

$$
E=\frac{J}{b}=\frac{I}{b \sigma \omega_{2}}
$$

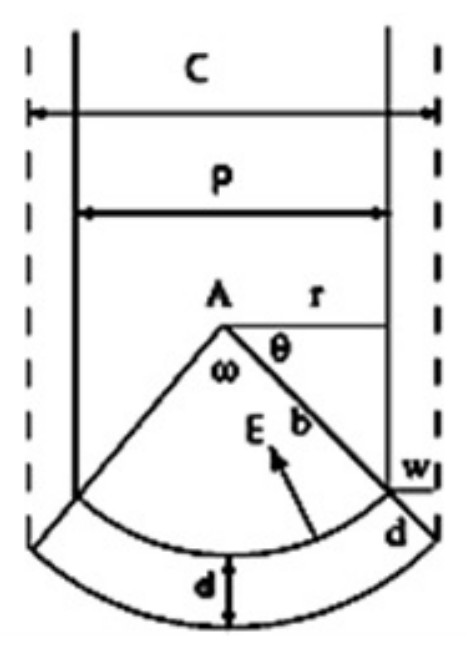

FIG. 1. Schematic drawing of the cross section a nanopore 


\subsection{Current - time diagram}

As shown in Fig. 2, the current drastically decreases as the anodizing duration increases. The reduction is due to the formation of a barrier layer with high electric resistance on the aluminum surface. As the thickness of the layer increases, the voltage approaches its minimum value. Then, the oxide layer is partially cracked, leading to a voltage increment (Fig. 2). The cracks made on barrier layer are responsible for pore formation. On the other hand, the cracks themselves are formed after dissolution of areas of barrier layer having physical and/or chemical defects. When no more cracks are going to be created, the current reaches a steady state (Fig. 2, the horizontal lines at $t>50 \mathrm{~s}$ ) in which the pore growth initiates. In two-step anodizing, all pores grow in the same direction. This is because of the reaction related to the oxide layer formation and its dissolution simultaneously in myriads of pores, leading to an equilibrium state. In fact, there is a uniform electric area in all pores which arranges the pores in an equidistant arrangement from each other.

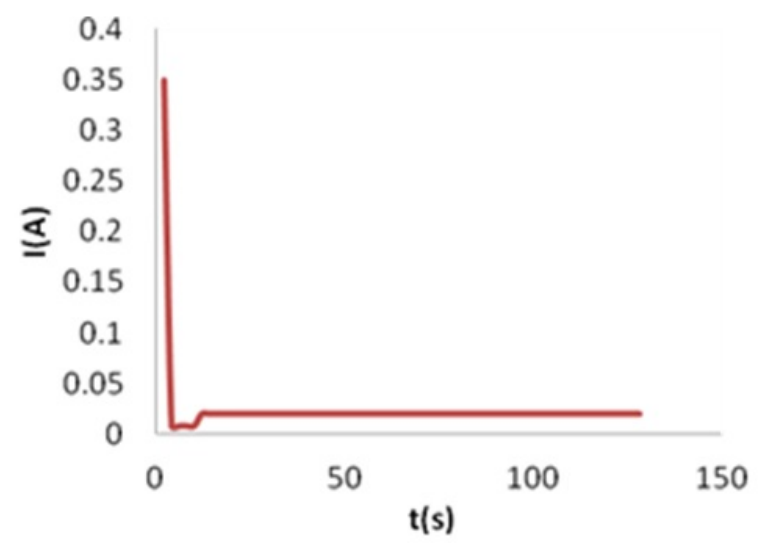

FIG. 2. Current density-time curve of the second anodic oxidation process at $40 \mathrm{~V}$ and $0.3 \mathrm{M}$ $\mathrm{H}_{2} \mathrm{C}_{2} \mathrm{O}_{4}$ at $17^{\circ} \mathrm{C}$

\subsection{Barrier layer opening}

The SEM images of the anodic alumina generated by anodization at $40 \mathrm{~V}$ are shown in Fig. 3a. The average pore diameters at this voltage were calculated to be $62 \mathrm{~nm}$. The SEM pattern also shows that the thickness of the oxide layer under these conditions was about $80.9 \mu \mathrm{m}$ (Fig. 3b).

To investigate structural changes that occurred during the pore opening process, a series of SEM images of the barrier oxide layer were taken at different time intervals representing different stages of barrier layer dissolution, and these are presented in Fig. 4.

The SEM image (Fig. 4b) of the barrier layer after about 30 minutes of etching did not show morphological differences in comparison with structures prior to etching (Fig. 4a). After $60 \mathrm{~min}$ of etching, the barrier layer is finally breached by the acid (Fig. 4c). Note that the initial opening is uneven across the surface. The majority of the cells have an opening of $57 \mathrm{~nm}$, while a few of the cells remain closed. The structure of the barrier layer after 90 minutes of etching, is completely removed (Fig. 4d).

The XRD patterns for the anodic alumina generated by anodization at $40 \mathrm{~V}$ are shown in Fig. 5. There is no peak for nanoporous alumina except the peak of aluminum basis and the amorphous oxide layer. The oxide layer is fragile (ruptured) owing to its amorphous structure.

\section{Conclusion}

In this work, it has been shown that through a highly-controlled process, the chemical etching of the AAM barrier layer can be performed in such a way as to achieve nanometer scale control of the pore opening. The time resolved dissolution of the barrier oxide film was characterized by SEM. This method has the potential to significantly improve existing pore opening procedures based on time-controlled etching and to improve the reproducibility in the fabrication of AAM membranes having desired pore diameters, particularly when AAM is synthesized using different anodization conditions. 


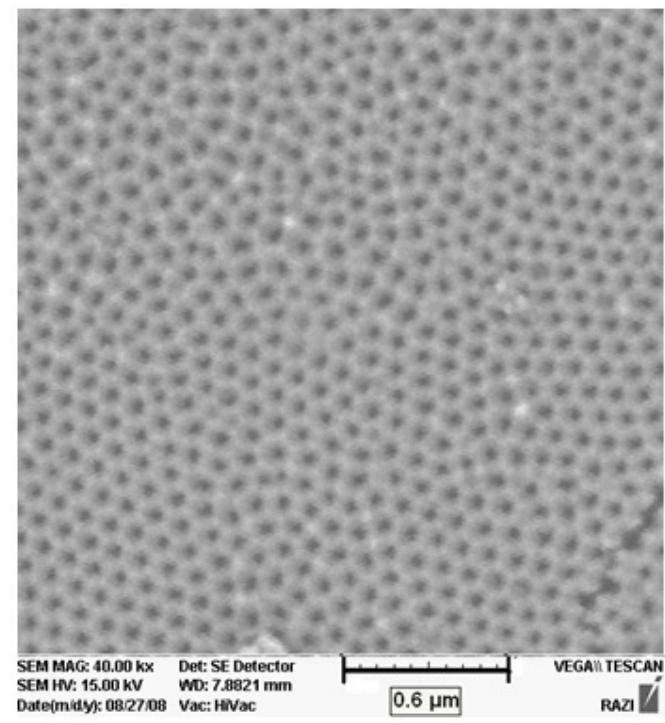

a

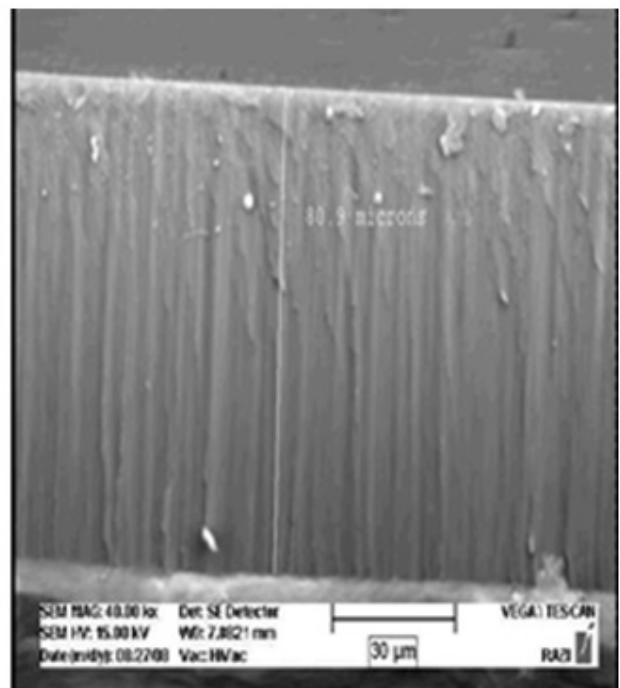

b

FIG. 3. SEM images of surface (a) and cross section b) of anodic alumina at anodizing conditions of $40 \mathrm{~V}, 0.3 \mathrm{M} \mathrm{H}_{2} \mathrm{C}_{2} \mathrm{O}_{4}, 17{ }^{\circ} \mathrm{C}, 24$ hours

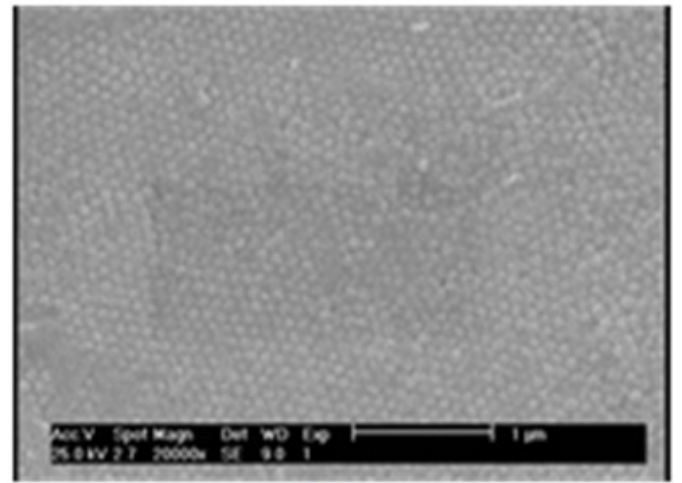

a

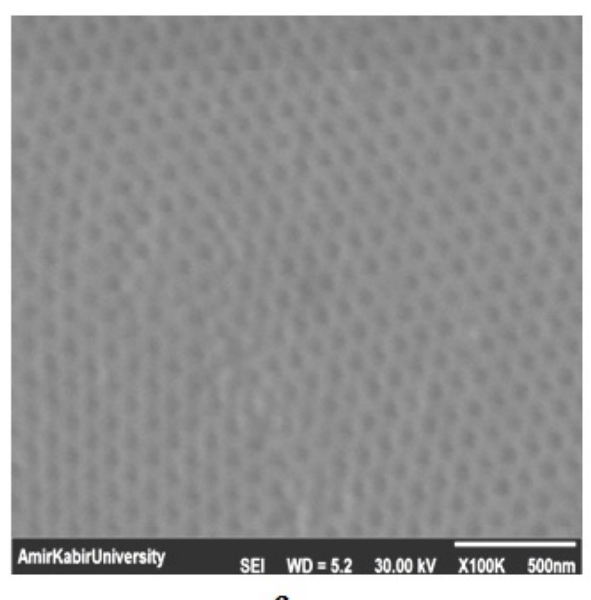

c

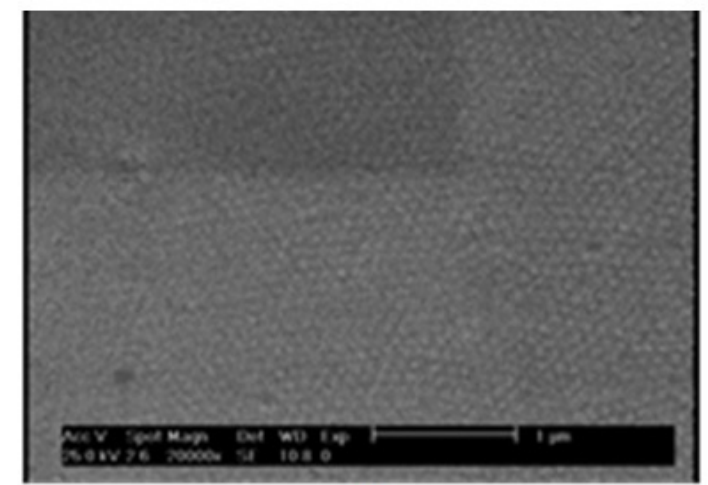

b

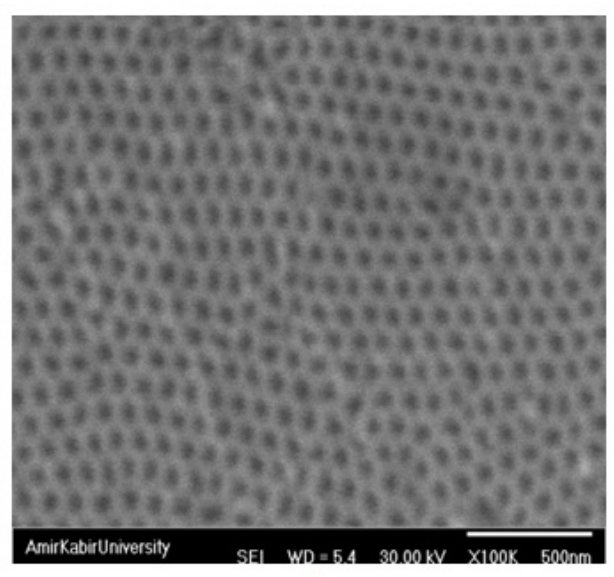

d

FIG. 4. Bottom surfaces of specimens after barrier layer removal for different processing times. a) $0 \mathrm{~min} \mathrm{b)} 30 \mathrm{~min} \mathrm{c)} 60 \mathrm{~min} \mathrm{d)} 90 \mathrm{~min}$ 


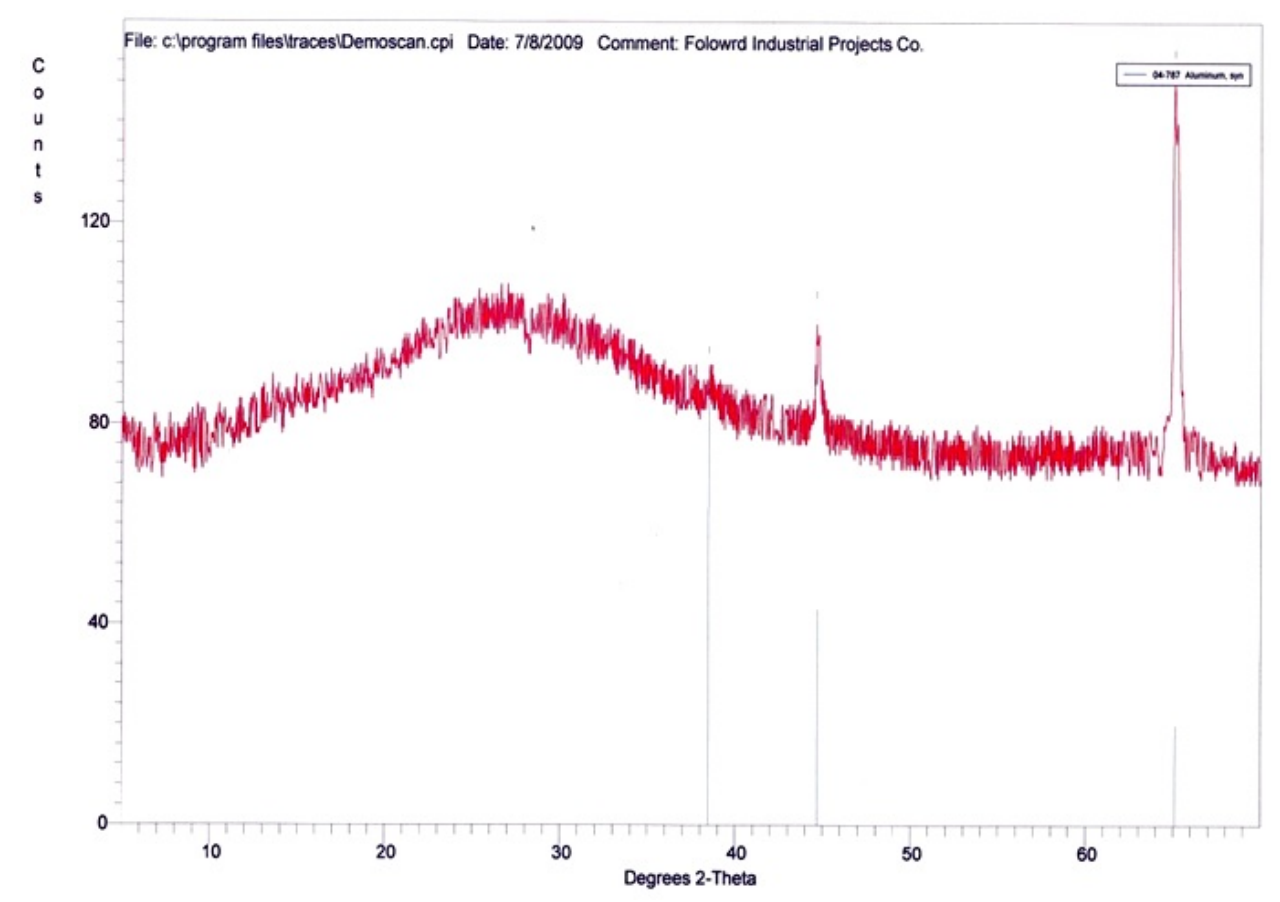

FIG. 5. X-ray diffraction patterns of alumina formed by two step anodizing process

\section{References}

[1] Reidenbach F. Surface Engineering. ASM International, Ohio, 2007, p. 124.

[2] Itaya K., Sugawara S., Arai K., and Saito S. Properties of porous anodic aluminum oxide films asmembrances. Journal of Chemical Engineering of Japan, 1984, 17(6), P. 514-520.

[3] Masuda H., Yada K. and Osaka A. Self-Ordering of Cell Conguration of Anodic Porous Aluminawith Large-Size Pores in Phosphoric Acid Solution. Japanese Journal of Applied Physics, 1998, 37, P. 212-219.

[4] Keller F., Hunter M.S., Robinson D.L. Structural Features of Oxide Coatings on Aluminum. The Electrochemical Society, 1953, 100(9), P. 411-419.

[5] Crouse D., Lo Y.H., Miller A.E., Crouse M. Self-ordered pore structure of nodized aluminum on silicon and pattern transfer. Appl. Phys. Lett, 2000, 76(1), P. 49-51.

[6] Qin D., Lu M., Li. H. Magnetic force microscopy of magnetic domain structure in highly ordered Conanowire arrays. Chem. Phys. Lett, 2001, 350, P. 51-56.

[7] Imai T., Nomura S. Quantum dot arrays prepared with self-organized nanopore and its photoluminescence spectra. Physica E: Lowdimensional Systems and Nanostructures, 2004, 21, P. 1093-1097.

[8] Steinhart M., Wehrspohn R.B., Gosele U., Wendor J. Nanotubes by Template Wetting: A Modular Assembly System. Chem. Int. Ed., 2004, 43, P. 1334-344.

[9] J. Justin Gooding. Nanostructuring electrodes with carbon nanotubes: A review on electrochemistry and applications for sensing. Electrochim. Acta, 2005, 50, P. 3049-3060.

[10] Gong D., Yadavalli V., Paulose M., Pishko M., Grimes C. Controlled molecular release using nanoporous alumina, Biomed. Microdevices, 2003, 5, P. 75-80.

[11] Darder M., Aranda P., Hernandez-Velez M., Manova E., Ruiz-Hitzky E. Encapsulation of enzymes in alumina membranes of controlled pore size. Thin Solid Films, 2005, 495, P. 321-326.

[12] Bocchetta P., Ferraro R., F. Di Quarto. Advances in anodic alumina membranes thin film fuel cell: $\mathrm{CsH}_{2} \mathrm{PO}_{4}$ pore-filler as proton conductor at room temperature. Power Sources, 2009, 187, P. 49-56.

[13] Zheng M.J., Zhang L.D., Li G.H., Shen W.Z. Fabrication and optical properties of large-scale uniformzinc oxide nanowire arrays by one-step electrochemical deposition technique. Chemical Physics Letters, 2002, 363, P. 123-128.

[14] Lee W., Ji R., Gosele U., Nielsch K. Fast fabrication of long-range ordered porous alumina membranesby hard anodization. Nature Materials, 2006, 5, P. 741-747.

[15] Vrubevsky I., Parkoun V., Schreckenbach J., Marx G. Study of porous oxide film growth on aluminum in oxalic acid using a re-anodizing technique. Applied Surface Science, 2004, 227, P. 282-292.

[16] O'Sullivan J.P. and Wood G.C. The Morphology and Mechanism of Formation of Porous Anodic Films on Aluminium. Proceeding of the Royal Society, 1970, P. 511-544. 